\title{
Impact of Nurse Horizontal Violence and Coping Strategies: A Review
}

\author{
Xi Zhang, Lijuan Xiong* \\ Department of Medicine, Yangtze University, Jingzhou, China \\ Email: *xhxlj@126.com
}

How to cite this paper: Zhang, $\mathrm{X}$. and Xiong, L.J. (2019) Impact of Nurse Horizontal Violence and Coping Strategies: A Review. Yangtze Medicine, 3, 289-300. https://doi.org/10.4236/ym.2019.34028

Received: May 7, 2019

Accepted: September 14, 2019

Published: September 17, 2019

Copyright $\odot 2019$ by author(s) and Scientific Research Publishing Inc. This work is licensed under the Creative Commons Attribution International License (CC BY 4.0).

http://creativecommons.org/licenses/by/4.0/

\begin{abstract}
Horizontal violence is widespread in nursing with deep influences. Foreign studies on horizontal violence among nurses are rich in content, including epidemic characteristics, influencing factors, impacts, intervention measures, experiences, etc. However, domestic studies are limited to current situation investigation and influencing factors. Research on intervention measures is very lacking. In this paper, horizontal violence relevant literatures at home and abroad were reviewed, and the epidemiological characteristics, effects and strategies adopted abroad were summarized, to provide references for domestic researches.
\end{abstract}

\section{Keywords}

Nurse, Horizontal Violence, Lateral Violence, Literature Review

\section{Introduction}

Nurses play an important role in ensuring patient safety. However, the safety of nurses themselves deserves deep consideration. The American Nurses Association proposed that every nurse has the right to work in a safe environment, which is a prerequisite for providing high-quality patient care [1]. Horizontal violence can destroy the safety culture and welfare of nurses in work units. In recent years, the "nurse-centered" magnet hospital model has been strongly supported and developed at home and abroad. Improving the nurse practice environment has become the most effective means for managers to improve the job satisfaction of nurses and reduce the turnover rate of nurses [2], while horizontal violence causes interpersonal conflicts among nurses in work units, which destroys the humanistic environment of nurses. The workplace violence of nurse comes from a variety of sources. Researches show that horizontal violence from 
nurses' colleagues is more destructive, compared with patients and their families [3] [4]. In the past 3 decades, although there have been many studies on horizontal violence, the incidence of horizontal violence has not been solved, which deserves attention [5]. Now the author takes "horizontal violence", "lateral violence", "bulling", "incivility behaviour", "nurse" as keywords to search Pubmed, EMbase, CBM, CNKI databases for relevant literatures. The process and results of screening articles are listed in Figure 1. The current situation of horizontal violence, its impact and the coping strategies adopted abroad are summarized as follows.

\section{Current Situation of Horizontal Violence among Nurses}

\subsection{Overview of Horizontal Violence}

Horizontal violence is one of the types of violence in the medical workplace violence [6]. It is violence among nurses employees. It usually refers to the phenomenon of interpersonal conflicts or conflicts among colleagues. It is also known as lateral violence, bullying, incivility behaviors in foreign studies. It occurs widely, between two individuals in a group, or for a member. In previous studies, due to a lack of a unified definition of horizontal violence, although the term "horizontal violence" is not used in many articles, the behavior described in its research content is indeed horizontal violence. Horizontal violence is composed of a group of negative, harmful behaviors among peers. Its purpose is to isolate and exclude the target, usually based on verbal and emotional abuse. Bullying is a persistent behavior. Its operational definition is repeated (at least once a week) and continuous (not less than six months) destructive behavior. In

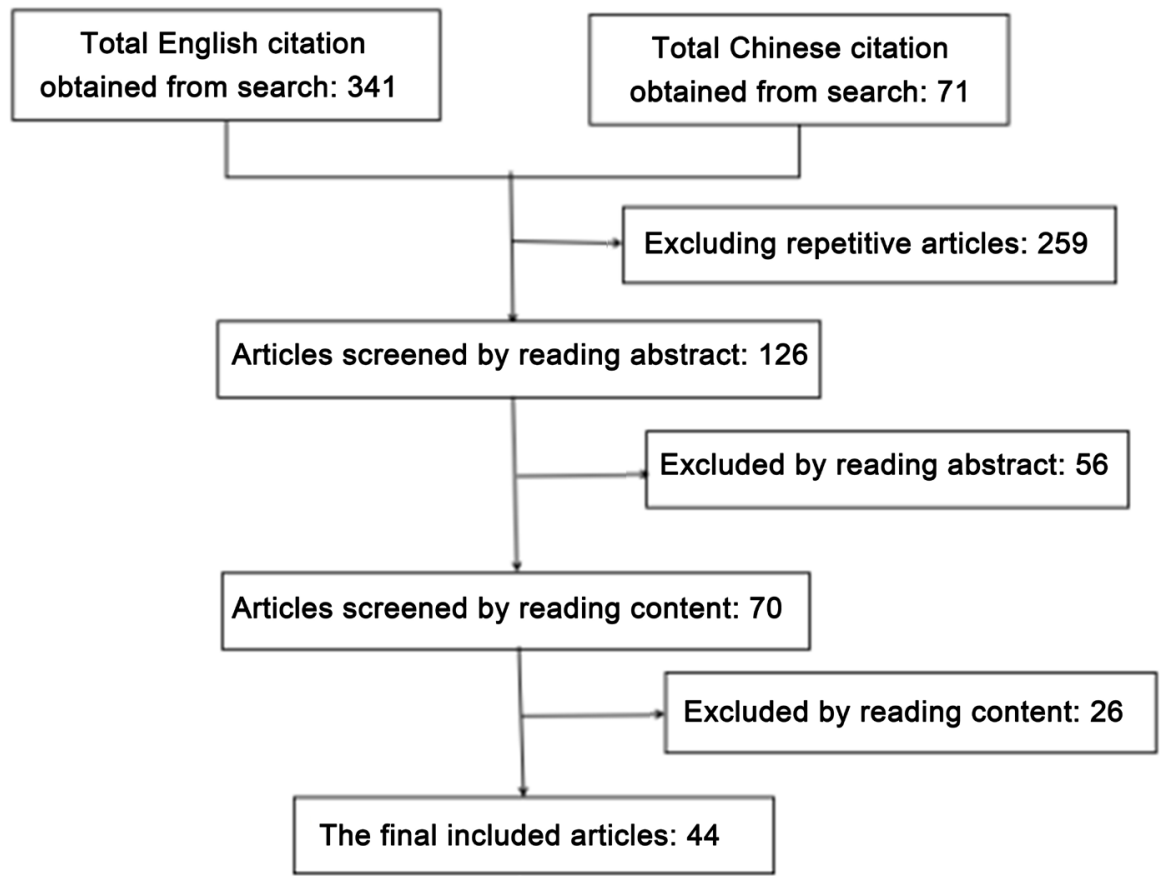

Figure 1. The process and results of screening articles. 
summary, the difference between horizontal violence and bullying is that horizontal violence is an isolated or single negative action event [7].

\subsection{The Forms of Horizontal Violence}

Forms of horizontal violence are widely, in Ebrahimi's study [8], horizontal violence was classified into three categories, including psychological violence, verbal violence and physical violence. Domestic study [9] divided horizontal violence into explicit and invisible forms. At present, there is no consistent standard for the forms of horizontal violence, and there are some differences among various researches. The author summarizes 24 forms of horizontal violence based on relevant literatures at home and abroad, as is shown in Table 1.

\subsection{Epidemiological Characteristics of Horizontal Violence}

Horizontal violence is common in the nursing profession and can occur at all levels of nurses. And it has been proved to be a global problem, however, the prevalence of horizontal violence is different from countries, Bambi's study [10] in 25 of the related literature of horizontal violence in summary, the results showed that the incidence of horizontal violence ranges from $1 \%$ to $87.4 \%$, the prevalence of horizontal violence in the United States is as high as $87.4 \%$, while in Europe and Italy the prevalence is less than $10 \%$, to analyse, the reasons may be the inconsistent definitions of the research on horizontal violence, different research tools, in addition there exist certain differences in culture between countries. After that, Bambi [11] conducted a survey on 930 nurses in Italy and found that $35.8 \%$ of them had experienced horizontal violence within one year, and most of them reported at least two perpetrators, and highly educated nurses were more likely to suffer from horizontal violence. Longod [12] explored the

Table 1. Forms of horizontal violence.

\begin{tabular}{|c|c|}
\hline withholding information & discourage enthusiasm \\
\hline humiliate or ridicule & continuing criticism \\
\hline $\begin{array}{l}\text { command others to do work that is beyond } \\
\text { their abilities }\end{array}$ & ignore the opinions of others deliberately \\
\hline spread malicious gossip & make mischief \\
\hline neglect, exclusion or isolation & excessive monitoring of other's work \\
\hline talk or whispers behind one's back & undermine others' chances of success or promotion \\
\hline public dressing down & blocking access to resources \\
\hline release anger on others & joke excessively \\
\hline threaten or intimidate & scapegoat \\
\hline refusing to help & biased report \\
\hline $\begin{array}{l}\text { leaking or offensive comments about other's } \\
\text { privacy }\end{array}$ & ethnic discrimination \\
\hline tell someone to quit their job & physical violence (eg: throwing, pushing, spitting) \\
\hline
\end{tabular}


experience of horizontal violence of the head nurse and found that the head nurse, like other ordinary nurses, would experience different levels of horizontal violence at work too.

In domestic studies, nurses generally experience horizontal violence. Woo [13] investigated 127 nurses in the department of neurosurgery and found that 105 nurses (82.7\%) had experienced different types and levels of horizontal violence in the past year. Li [14] investigated 136 surgical nurses, and the results showed that the incidence of horizontal violence was as high as $70.6 \%$. In addition, $\mathrm{Ma}$ [15] studies on horizontal violence among pediatric nurses also showed that horizontal violence was widespread. In addition, three literatures all pointed out that nurses with low seniority were the subjects of high incidence of horizontal violence.

Although studies have found a high incidence of lateral violence, The occupational safety and health administration of the United States points out that because the reporting process of organizations is not sound, victims are afraid of retaliation, and horizontal violence is generally underestimated, and low reporting rate is common [16]. Then, why is horizontal violence so popular in nursing? The reasons may be related to the following points. Firstly the strict hierarchical system in nursing leads to unequal powerment among nurses, especially junior nurses and nurse students, who are vulnerable to be bullied. Secondly, nurses have a heavy workload and a low status in their work, which inevitably leads to some negative emotions, then horizontal violence arise in the process of emotional release [17]. In addition, most of the nurses are female who are more sensitive and emotional. They often overreact to minor things, resulting in intensive interpersonal relationships.

\section{The Impact of Horizontal Violence}

\subsection{Nurses' Physical and Mental Health}

Horizontal violence has negative psychological and physical effects on the health of nurses. It often does not directly attack nurses physically, but indirectly puts victims in a state of high level stress, leading to stress-related disorders and injuries. Physiologically, repeated exposure to stressors depletes the body's defense system and increases the risk of heart disease, hypertension, sleep disorders and other adverse reactions to stress [18]. Psychologically, victims of horizontal violence generally have a low level of mental health, and horizontal violence may cause obvious psychological symptoms for nurses, such as anxiety, depression and feeling of stress [19]. It has been reported that the most severe response to horizontal violence is post-traumatic stress disorder [20]. In addition, it is worth noting that people who have witnessed the occurrence of horizontal violence will also have similar responses to the victims of horizontal violence. Cardoso [21] investigated and analyzed the witnesses of horizontal violence and found that the witnesses are the second victims of horizontal violence, and they will also experience similar complaints and psychological barriers. 


\subsection{The Quality of Nursing Service}

The influences of horizontal violence on patients are of particular concern. Several studies have shown that horizontal violence and other incivility workplace behaviors can affect patient outcomes. Bloom [22] interviewed seven nurses in the United States who had experienced horizontal violence in his study, and analyzed that the occurrence of horizontal violence would make nurses feel painful, their attention and judgment would be disturbed, and the communication and collaboration among nursing staffs would be reduced, which would eventually damage patient care. Laschinger [23] conducted a survey on 336 nurses in the emergency department and found that horizontal violence had a significant impact on the incidence of adverse nursing events and the quality of nursing services, and nurses were more likely to send wrong drugs, check errors and other events affecting patient safety.

\subsection{The Development and Management of the Nursing}

According to the US Bureau of labor statistics, currently there are about 3.6 million registered nurses in the US by 2022 , it is expected that more than half a million registered nurses will retire, which will create a labor gap for nearly 1 million new registered nurses [24]. Thus it can be seen that newly liscenced nurses are of great importance to the construction and development of nursing. Several studies have shown that compared with experienced nurses, newly liscenced nurses are more likely to be influenced by the working environment and choose to leave their position [25] [26]. This will result in the loss and shortage of nursing staff and hinder the development of the nursing. On the other hand, horizontal violence will lead to negative interpersonal relationships among nurses, which will reduce nurses' career satisfaction and patients' satisfaction with nursing services [27], which will damage the team atmosphere of nursing unit, damage the reputation of nursing industry, and increase the difficulty of nursing management.

\subsection{Health Care Organization}

Health care organizations experience a financial burden when employees are impacted by workplace incidences like horizontal violence. Indvik [28] pointed out that horizontal violence increased the risk of sick leave and dimission of nurses, caused direct economic losses to medical institutions. In addition, the recruitment and training of newly liscenced nurses also generated costs. It is reported that the cost caused by the resignation of a registered nurse is not less than $\$ 20,000[29]$.

\section{Horizontal Violence Coping Strategies Abroad}

There is one research on the intervention of horizontal violence in China at present, coping strategies studied abroad are rich including: Education intervention, Leadership style and behaviors, policies. Basic informations of reviewed ar- 
ticles are listed in Table 2.

\subsection{Education Intervention}

\subsubsection{Curriculum}

By integrating bullying information and knowledge into the prelicensure nursing curriculum may help change the perception of bullying from an acceptable part of nursing to intolerable and unprofessional behavior. Nikstaitis [30] used didactic teaching courses to provide nurses in intensive care units with skills to cope with and manage horizontal violence. The results showed that nurses' understanding of horizontal violence was not significantly different statistically, but the data showed that nurses' ability to recognize horizontal violence was slightly improved. However, in the study of Ceravolo [31] et al., beneficial results have been achieved in providing education for nurses. They presented nurses with information on horizontal violence, communication and conflict resolution in the form of workshops. As a result, the incidence of verbal violence dropped from $90 \%$ to $76 \%$, the nurses' opinions were respected and the working atmosphere improved.

\subsubsection{Problem Based Learning}

Problem-based learning is an additional educational intervention that has been

Table 2. Basic information of coping strategies included in the literatures.

\begin{tabular}{|c|c|c|}
\hline research & design & conclusion \\
\hline Nikstaitis 2014 & $\begin{array}{l}\text { A quantitative pilot study } \\
\text { between } 21 \text { nurses }\end{array}$ & $\begin{array}{l}\text { Educational intervention can improve nurses' } \\
\text { awareness of incivility }\end{array}$ \\
\hline Ceravolo 2012 & $\begin{array}{l}\text { A quantitative study in inpatient } \\
\text { nurses }\end{array}$ & $\begin{array}{l}\text { Educational workshops that enhanced } \\
\text { awareness of lateral violence and improved } \\
\text { assertive communication }\end{array}$ \\
\hline Clark 2014 & $\begin{array}{l}\text { A qualitative study describing } \\
\text { how knowledge gained from the } \\
\text { Problem based learning (PBL) }\end{array}$ & $\begin{array}{l}\text { A PBL scenario was an effective teaching } \\
\text { strategy for preparing new graduates to address } \\
\text { nurse-to-nurse incivility in the practice setting. }\end{array}$ \\
\hline Kang 2017 & $\begin{array}{l}\text { A randomized controlled trial } \\
\text { was performed between } \\
40 \text { nurses }\end{array}$ & $\begin{array}{l}\text { The cognitive rehearsal for workplace bullying } \\
\text { improves interpersonal relationships and } \\
\text { decreases turnover intention }\end{array}$ \\
\hline Griffin 2014 & $\begin{array}{l}\text { A review the use of cognitive } \\
\text { rehearsal }\end{array}$ & $\begin{array}{l}\text { Cognitive rehearsal was revisited as a shield } \\
\text { for incivility and lateral violence }\end{array}$ \\
\hline Kennedy 2015 & $\begin{array}{l}\text { A review to state the role of } \\
\text { empowerment in improving the } \\
\text { clinical environment }\end{array}$ & $\begin{array}{l}\text { Empowerment can contribute positively to } \\
\text { improving the environment in which } \\
\text { care is provided }\end{array}$ \\
\hline Wing 2015 & $\begin{array}{l}\text { A predictive, non-experimental } \\
\text { study in } 394 \text { new graduate nurses }\end{array}$ & $\begin{array}{l}\text { Empowering workplaces contribute to lower } \\
\text { mental health symptoms in new graduate } \\
\text { nurses, empowerment was significantly } \\
\text { negatively correlated with supervisor incivility }\end{array}$ \\
\hline Myers 2016 & $\begin{array}{l}\text { A qualitative study to explore } \\
\text { nurses' experiences of horizontal } \\
\text { violence }\end{array}$ & $\begin{array}{l}\text { Nurse managers need to be the culture } \\
\text { champions who hold individuals accountable } \\
\text { for HV and foster professionalism through } \\
\text { their leadership }\end{array}$ \\
\hline
\end{tabular}


shown to mitigate the effects of horizontal violence. It involves self-learning and group discussion, with the aim not to solve the problem raised but to increase the overall understanding of the problem raised [32]. Clark et al. [33] conducted a 10-month follow-up study on this method among new nurses, and found that newly licensed nurses developed positive methods to manage horizontal violence, and believed that problem-based learning was an effective method to guide students and newly licensed nurses to deal with horizontal violence.

\subsubsection{Cognitive Rehearsal}

Cognitive rehearsal is a technique commonly used in cognitive behavioral therapy, in which individuals rehearse specific situations to practice appropriate interactions or positive coping processes. Cognitive rehearsal consists of four stages: developing scenarios, determining communication standards, role-playing and feedback evaluation [34]. Kang [35] used the cognitive rehearsal as interventions, 40 nurses for randomized controlled trials, the results showed that the cognitive preview can effectively improve the nurses' interpersonal relations, reduce the turnover intention, but does not prevent the nurse lateral violence or symptoms of the experience, analyze the causes, may be factors affecting horizontal organization of violence was not well controlled, and lateral violence experience symptoms of change will take long time. In Griffin's [36] study, the article updated the literature on cognitive rehearsal and reviewed the use of cognitive rehearsal, suggesting that Cognitive rehearsal was revisited as a shield for incivility and lateral violence, and the use of cognitive rehearsal as a strategy for addressing incivility and bullying behaviors in nursing continues to be a valuable tool.

\subsection{Leadership Style and Behaviors}

\subsubsection{Empowerment of Nurses}

Leaders play a key role in organizational culture and atmosphere, and transformational leaders can create a more positive interpersonal relationship and work environment. The main feature of transformational leadership is empowerment, which is an important method to improve the work efficiency of employees and achieve individual and collective goals [37]. Empowerment refers to the reasonable distribution of power and control, increasing the channels for employees to obtain information and resources, constantly providing opportunities for employees' development, and creating a favorable working environment for employees. A number of studies [38] [39] [40] have pointed out that empowerment can improve nurses' job satisfaction, tap into practical autonomy, enhance professional cooperation among nurses, and play an important role in the prevention of horizontal violence. Especially in Wing's study [40], 320 nurses were examined, finding that empowering workplaces not only contribute to lower levels of mental health symptoms for new graduate nurses, but also had a significant negative relationship with both supervisor incivility and co-worker incivility. 


\subsubsection{Nursing Leaders Involved}

In health care settings, solutions to horizontal violence include the direct involvement of nursing leaders. Myers et al. [41] believe that nursing management needs to develop known strategies and adopt evidence-based interventions as a means to combat horizontal violence. Edmonson et al. [42] also advocate the participation of nursing managers. The participation of nursing managers is an important part of combating horizontal violence.

\subsection{Policies}

The development and implementation of policies on uncivil behaviours in the workplace is a major strategy that organizations should adopt. Although the joint commission advocates for policies on various types of workplace incivility, research on such interventions is lacking in the nursing literature. Rocker [43] believes that medical institutions should adopt an attitude and policy that does not tolerate horizontal violence to solve this problem. In 2009, agencies were required to implement a code of conduct for negative behaviors [44]. Entitled Healthy Workplace Bill (HWB) is a proposed legislation in the US Congress in order to protect adult employees who have experienced abuse in the workplace setting.

\section{Enlightenment on Domestic Nursing}

Horizontal violence has been proven to be widespread in the nursing profession and can occur at all levels of the nursing profession. According to the national nursing development plan (2016-2020) formulated by the National Health and Family Planning Commission, the development of nursing in China is faced with the challenge of the relatively insufficient number of nurses. And tense doctor-patient relationship in our country, when nurses are suffering the external violence from patients and their families, horizontal violence from their colleagues is happening at the same time, this will undoubtedly cause tremendous pressure to nurses, then inevitably lead to the nurse's staff turnover, therefore, lateral violence among nurses needs to be solved urgently.

Nursing managers in alleviating lateral violence plays a vital role, the manager's behavior is an example to nurses, the biggest influence of horizontal violence is building team cooperation awareness between nursing administrators and nurses, managers can prevent horizontal violence through participating in unit of daily affairs and work flow, creating a strong sense of teamwork between staff and supervisor; working together to complete tasks or make decisions, empowering staff by asking for input and making decisions based on staff feedback, establishing close relationship with employees, etc. In addition, nurses' cognition of horizontal violence is insufficient, most nurses think horizontal violence as part of their work mistakenly, even unable to identify these behaviors, thus can't deal with it correctly [45], therefore, raising nurses' awareness of horizontal violence is the first step to solve the problem. Domestic scholar Wang [46], con- 
ducted educational training for 55 nurse students, teaching them the knowledge and prevention skills related to horizontal violence, the result showed an improvement of their coping skills, the effect of preventing the occurrence of horizontal violence was not measured.

\section{Conclusion}

Horizontal violence is a challenge and threat to nursing, deserving more attention of domestic nurses and managers. In the following studies, the depth and breadth of the research should be increased, large sample surveys and interviews should be conducted, and interventions in line with the condition of nursing in China should be further explored.

\section{Conflicts of Interest}

The authors declare no conflicts of interest regarding the publication of this paper.

\section{References}

[1] American Nurses Association (2010) House of Delegates Resolution: Hostility, Abuse and Bullying in the Workplace.

[2] Wang, Y., Ji, X.J., Dai, H.H., et al. (2018) Application of Magnetic Hospital Concept in Clinical Nursing Management. Journal of Qilu Nursing, 24, 11-15.

[3] Farrell, G.A. (1999) Aggression in Clinical Settings: Nurses' Views-A Follow up Study. Journal of Advanced Nursing, 29, 532-541. https://doi.org/10.1046/j.1365-2648.1999.00920.x

[4] Pien, L.C., Cheng, Y. and Cheng, W.J. (2019) Internal Workplace Violence from Colleagues Is More Strongly Associated with Poor Health Outcomes in Nurses than Violence from Patients and Families. Journal of Advanced Nursing, 75, 793-800. https://doi.org/10.1111/jan.13887

[5] Roberts, S.J. (2015) Lateral Violence in Nursing: A Review of the Past Three Decades. Nursing Science Quarterly, 28, 36-41. https://doi.org/10.1177/0894318414558614

[6] Phillips, J.P. (2016) Workplace Violence against Health Care Workers in the United States. New England Journal of Medicine, 374, 1661-1669. https://doi.org/10.1056/NEJMra1501998

[7] Taylor, R.A. and Taylor, S.S. (2018) Reframing and Addressing Horizontal Violence as a Workplace Quality Improvement Concern. Nursing Forum, 53, 459-465. https://doi.org/10.1111/nuf.12273

[8] Ebrahimi, H., Hassankhani, H., Negarandeh, R., et al. (2017) Violence against New Graduated Nurses in Clinical Settings: A Qualitative Study. Nursing Ethics, 24, 704-715. https://doi.org/10.1177/0969733015624486

[9] Li, X.Y., Li, W.T. and An, L.B. (2009) The Research on Current Status Investigation and Countermeasures of Lateral Violence among Nurses. Journal of Chinese Nursing, 44, 886-888.

[10] Bambi, S., Foà, C., Felippis, C.D., et al. (2018) Workplace Incivility, Lateral Violence and Bullying among Nurses. A Review about Their Prevalence and Related Factors. Acta BioMedica, 89, 51-79. 
[11] Bambi, S., Guazzini, A., Piredda, M., et al. (2019) Negative Interactions among Nurses: An Explorative Study on Lateral Violence and Bullying in Nursing Work Settings. Journal of Nursing Management, 27, 749-757. https://doi.org/10.1111/jonm.12738

[12] Longo, J., Cassidy, L. and Sherman, R. (2016) Charge Nurses' Experiences with Horizontal Violence: Implications for Leadership Development. Journal of Continuing Education in Nursing, 47, 493-499. https://doi.org/10.3928/00220124-20161017-07

[13] Wu, L., Hu, H.C. and Sun, Y.J. (2017) Investigation and Analysis of Horizontal Violence Experienced by Neurosurgical Nurses. Nursing Journal of Chinese People Liberation Army, 34, 34-37.

[14] Li, H. and Yu, R.J. (2017) Effects of Horizontal Violence on Low Health Related Work Efficiency of Surgical Contract Nurses. Journal of Nursing Research, 31, 4271-4273.

[15] Ma, X.H., Yao, Y.J., Yang, X.N., et al. (2019) Investigation and Analysis of Horizontal Violence Status and Influencing Factors in Pediatric Nurses. Journal of Nursing Management, 19, 108-110.

[16] Occupational Safety and Health Administration (OSHA) (2015) Workplace Violence in Healthcare. 3826.

[17] Trépanier, S.-G., Fernet, C., Austin, S. and Boudrias, V. (2016) Work Environment Antecedents of Bullying: A Review and Integrative Model Applied to Registered Nurses. International Journal of Nursing Studies, 55, 85-97. https://doi.org/10.1016/j.ijnurstu.2015.10.001

[18] Sauer, P.A. and McCoy, T.P. (2017) Nurse Bullying: Impact on Nurses' Health. Western Journal of Nursing Research, 39, 1533-1546. https://doi.org/10.1177/0193945916681278

[19] Laschinger, H.K.S., Grau, A.L., Finegan, J., et al. (2010) New Graduate Nurses' Experiences of Bullying and Burnout in Hospital Settings: Bullying and Burnout in New Graduate Nurses. Journal of Advanced Nursing, 66, 2732-2742. https://doi.org/10.1111/j.1365-2648.2010.05420.x

[20] Laschinger, H.K.S. and Nosko, A. (2015) Exposure to Workplace Bullying and Post-Traumatic Stress Disorder Symptomatology: The Role of Protective Psychological Resources. Journal of Nursing Management, 23, 252-262. https://doi.org/10.1111/jonm.12122

[21] Cardoso, M., Fornés-Vives, J. and Gili, M. (2016) Implications of Psychological Harassment on Witnesses: An Observational Study in Nursing Staff. Enfermería Global, 15, 313-323.

[22] Bloom, E.M. (2019) Horizontal Violence among Nurses: Experiences, Responses, and Job Performance. Nursing Forum, 54, 77-83. https://doi.org/10.1111/nuf.12300

[23] Laschinger, H.K. (2014) Impact of Workplace Mistreatment on Patient Safety Risk and Nurse-Assessed Patient Outcomes. Journal of Nursing Administration, 44, 284-290. https://doi.org/10.1097/NNA.0000000000000068

[24] U.S. Bureau of Labor Statistics (2018) Registered Nurses: Summary.

[25] Kovner, C.T., Brewer, C.S., Fatehi, F., et al. (2014) What Does Nurse Turnover Rate Mean and What Is the Rate? Policy, Politics, \& Nursing Practice, 15, 64-71. https://doi.org/10.1177/1527154414547953

[26] Kovner, C.T., Djukic, M., Fatehi, F., et al. (2016) Estimating and Preventing Hospital Turnover of New Licensed Nurses: A Panel Survey. International Journal of Nursing Studies, 60, 251-262. https://doi.org/10.1016/j.ijnurstu.2016.05.003 
[27] Rosenstein, A.H. (2010) Measuring and Managing the Economic Impact of Disruptive Behaviors in the Hospital. Journal of Healthcare Risk Management, 30, 20-26. https://doi.org/10.1002/jhrm.20049

[28] Indvik, J. and Johnson, P.R. (2012) Lawsuits Walk in on Two Feet: The Bully in the Workplace. Journal of Organizational Culture, Communications and Conflict, 16, 63.

[29] Duffield, C.M., Roche, M.A., Homer, C., et al. (2014) A Comparative Review of Nurse Turnover Rates and Costs across Countries. Journal of Advanced Nursing, 70, 2703-2712. https://doi.org/10.1111/jan.12483

[30] Nikstaitis, T. and Simko, L.C. (2014) Incivility among Intensive Care Nurses: The Effects of an Educational Intervention. Dimensions of Critical Care Nursing, 33, 293-301. https://doi.org/10.1097/DCC.0000000000000061

[31] Ceravolo, D.J., Schwartz, D.G., Foltz-Ramos, K.M., et al. (2012) Strengthening Communication to Overcome Lateral Violence. Journal of Nursing Management, 20, 599-606. https://doi.org/10.1111/j.1365-2834.2012.01402.x

[32] Wood, D.F. (2003) Abc of Learning and Teaching in Medicine: Problem Based Learning. British Medical Journal, 326, 328-330. https://doi.org/10.1136/bmj.326.7384.328

[33] Clark, C.M., Ahten, S.M. and Macy, R. (2014) Nursing Graduates' Ability to Address Incivility: Kirkpatrick's Level-3 Evaluation. Clinical Simulation in Nursing, 10, 425-431. https://doi.org/10.1016/j.ecns.2014.04.005

[34] Smith, C.M. (2011) Scripts: A Tool for Cognitive Rehearsal. Journal of Continuing Education in Nursing, 42, 535-536. https://doi.org/10.3928/00220124-20111118-03

[35] Kang, J., Kim, J.I. and Yun, S. (2017) Effects of a Cognitive Rehearsal Program on Interpersonal Relationships, Workplace Bullying, Symptom Experience, and Turnover Intention among Nurses: A Randomized Controlled Trial. Journal of Korean Academy of Nursing, 47, 689-699. https://doi.org/10.4040/jkan.2017.47.5.689

[36] Griffin, M. and Clark, C.M. (2014) Revisiting Cognitive Rehearsal as an Intervention against Incivility and Lateral Violence in Nursing: 10 Years Later. Journal of Continuing Education in Nursing, 45, 535-542. https://doi.org/10.3928/00220124-20141122-02

[37] Grossman, S.C. (2013) Mentoring in Nursing: A Dynamic and Collaborative Process. 2nd Edition, Springer, New York.

[38] Beteh, J. and Heyliger, W. (2014) Academic Administrator Leadership Styles and the Impact on Faculty Job Satisfaction. Journal of Leadership Education, 13, 34-49. https://doi.org/10.12806/V13/I3/R3

[39] Kennedy, S., Hardiker, N. and Staniland, K. (2015) Empowerment an Essential Ingredient in the Clinical Environment: A Review of the Literature. Nurse Education Today, 35, 487-492. https://doi.org/10.1016/j.nedt.2014.11.014

[40] Wing, T., Regan, S. and Laschinger, H.K. (2015) The Influence of Empowerment and Incivility on the Mental Health of the New Graduate Nurse. Journal of Nursing Management, 23, 632-643. https://doi.org/10.1111/jonm.12190

[41] Myers, G., Côté-Arsenault, D., Worral, P., et al. (2016) A Cross-Hospital Exploration of Nurses' Experiences with Horizontal Violence. Journal of Nursing Management, 24, 624-633. https://doi.org/10.1111/jonm.12365

[42] Edmonson, C., Bolick, B. and Lee, J. (2017) A Moral Imperative for Nurse Leaders: Addressing Incivility and Bullying in Health Care. Nurse Leader, 15, 40-44. https://doi.org/10.1016/j.mnl.2016.07.012 
[43] Rocker, C.F. (2008) Addressing Nurse-to-Nurse Bullying to Promote Nurse Retention. The Online Journal of Issues in Nursing, 13, 1.

[44] Cardoso, M., Fornés-Vives, J. and Gili, M. (2016) Implications of Psychological Harassment on Witnesses: An Observational Study in Nursing Staff. Enfermería Global, 15, 313-323.

[45] Taylor, R.A. and Taylor, S.S. (2017) Enactors of Horizontal Violence: The Pathological Bully, the Self-Justified Bully and the Unprofessional Co-Worker. Journal of Advanced Nursing, 73, 3111-3118. https://doi.org/10.1111/jan.13382

[46] Wang, J., Wang, N., Ji, Y.Y., et al. (2017) Application of Case Study Method on Improving Intern Nurses Coping with Lateral Violence. Journal of Chinese Hospital, 21, 66-69. 